\title{
Analisa Nilai Hasil Terhadap Waktu pada Proyek Pembangunan Gedung Laboratorium FKIP Tahap IV (Lanjutan) Universitas Jambi
}

\author{
Siti Umi Azizah ${ }^{1}$, Fakhrul Rozi Yamali², Elvira Handayani ${ }^{3}$ \\ ${ }^{1}$ Mahasiswa Teknik Sipil Universitas Batanghari \\ ${ }^{2,3}$ Dosen Fakultas Teknik Universitas Batanghari \\ Correspondence email: fakhrul_65@yahoo.co.id
}

\begin{abstract}
Abstrak. Didalam pengendalian waktu dan pengendalian biaya pada suatu proyek sangat diperlukan agar suatu proyek mampu menyelesaikan proyek sesuai dengan waktu yang telah di rencanakan dan dengan biaya yang telah direncanakan. Metode analisis nilai hasil (Earned Value Analysis) adalah salah satu cara untuk mengetahui perkembangan proyek yang sedang berlangsung dengan menggunakan tiga indikator, yaitu ACWP, BCWS dan BCWP. Tujuan dari penelitian ini adalah untuk mengkaji dan mengendalikan waktu dan biaya serta memantau indeks kinerja proyek pelaporan pada pembangunan gedung laboratorium Fkip tahap IV (lanjutan) Universitas Jambi. Dari hasil perhitungan diperoleh nilai schedule variance (SV) sebesar (-14,88\%), hasil ini menunjukkan pelaksanaan pekerjaan terlambat dari jadwal rencana proyek. Nilai cost variance (CV) sebesar (-6,51\%), hasil ini menunjukkan biaya lebih besar dari anggaran yang telah di rencanakan. Nilai budget variace (BV) sebesar (7,28\%), hasil ini menunjukkan bahwa anggaran yang digunakan lebih besar dari pada anggaran yang telah direncanakan. Prakiraan waktu penyelesaian proyek (EAS) selama 26,29 minggu dengan prakiraan total waktu penyelesaian proyek 0,29 minggu, hal ini menunjukkan bahwa penyelesaian proyek lambat dari jadwal yang telah direncanakan, dengan nilai kontrak yaitu dalam kurun waktu 26 minggu. Untuk prakiraan biaya penyelesaian proyek (EAC) sebesar Rp. 18.512.224.334,00 dengan sisa anggaran yaitu Rp. -1.127.524.334,00, hal tersebut menunjukkan bahwa biaya yang dikeluarkan lebih besar dari anggaran pelaksanaan, dengan total anggaran biaya sebesar Rp. 17.384.700.000,00.
\end{abstract}

Kata Kunci: Metode Analisa Nilai Hasil, ACWP, BCWS, BCWP, SV, CV, BV, EAS, EAC

\section{PENDAHULUAN}

Manajemen konstruksi adalah perencanaan, penjadwalan dan pengendalian proyek, untuk mencapai tujuan proyek tersebut tanpa adanya penyimpangan. Manajemen harus membandingkan biaya, waktu, dan kinerja dari program terhadap rencana anggaran biaya, rencana waktu dan kinerja dalam setiap aktifitas. Manajemen konstruksi dapat diatur sesuai dengan sumber daya yang telah direncanakan yaitu tenaga kerja (manpower), peralatan (machine), metode (method), bahan (material), uang (money), dan pemasaran (market).

Dalam setiap proses pelaksanaan proyek, berhasil atau tidaknya proyek tersebut tergantung pada biaya, waktu dan mutu. Untuk biaya, perencana yang baik adalah perencana dimana dengan mengestimasi biaya proyek menghitung sampai sedetail-detailnya sampai yang kecil sekalipun. Waktu selalu berhubungan dengan biaya, apabila pekerjaan dapat dilaksanakan sesuai dengan waktu yang direncanakan akan memberikan keuntungan bagi pelaksanaan, tetapi jika melebihi dari waktu yang telah direncanakan maka akan menambah biaya pekerjaan.

Dengan adanya indikator proyek dari segi biaya dan waktu memungkinkan proyek berjalan sesuai dengan rencana. Karena pentingnya pengendalian proyek terhadap keberhasilan suatu proyek, maka proses pengendalian harus dapat dikerjakan secara cepat dan tepat agar setiap penyimpangan yang terjadi dapat cepat diidentifikasi dan dievaluasi secara cepat dan tepat. Pengendalian proyek yang tidak efektif diakibatkan karena kurangnya pendekatan yang serius terhadap teknik dan proses pengendalian, pada akhirnya akan didapatkan penyelesaian proyek dengan waktu terlampaui dan biaya yang tidak terkendali.

Didalam rumusan masalah penulis mengidentifikasi masalah yang akan dibahas dari hasil penelitian tersebut yaitu Mengevaluasi biaya dan waktu pada proyek Pembangunan Gedung Laboratorium FKIP tahap IV (Lanjutan) Universitas Jambi, Bagaimana penerapan EVA (Earned Value Analysis) untuk memperkirakan waktu akhir penyelesaian proyek setiap minggunya dengan mengacu pada indikator-indikator BCWS (Budgeted Cost of Work Schedule), BCWP (Budgeted Cost of Work Performed), dan ACWP (Actual Cost of Work Performed).

Adapun tujuan dari penelitian tersebut adalah Untuk mengkaji waktu dan biaya pada pembangunan gedung laboratorium FKIP tahap IV (lanjutan) Universitas Jambi, Memantau indek kinerja proyek pelaporan pada pembangunan gedung laboratorium FKIP tahap IV (lanjutan) Universitas Jambi.

\section{Metode Analisis Varians}

Metode analisis varians adalah metode untuk mengendalikan biaya dan jadwal suatu kegiatan pada proyek konstruksi. Dalam metode ini identifikasi dilakukan dengan membandingkan jumlah biaya sesungguhnya dikeluarkan terhadap anggaran. 
Siti Umi Azizah et al, Analisa Nilai Hasil Terhadap Waktu pada Proyek Pembangunan Gedung Laboratorium FKIP Tahap IV (Lanjutan) Universitas Jambi

\section{Analisis Nilai Hasil (Earned Value Analysis)}

Metode analisis nilai hasil digunakan untuk mengetahui sejauh mana proyek yang dilaksanakan tersebut sesuai dengan rencana atau tidak, salah satunya adalah memperkirakan waktu dan biaya. Menurut Iman Soeharto (2001), rumus Earned Value adalah sebagai berikut:

Nilai Hasil $=\%$ Penyelesaian $\times$ anggaran ..........................................................1

Keterangan :

1. \% penyelesaian adalah yang dicapai pada saat pelaporan

2. Anggaran adalah real cost biaya proyek

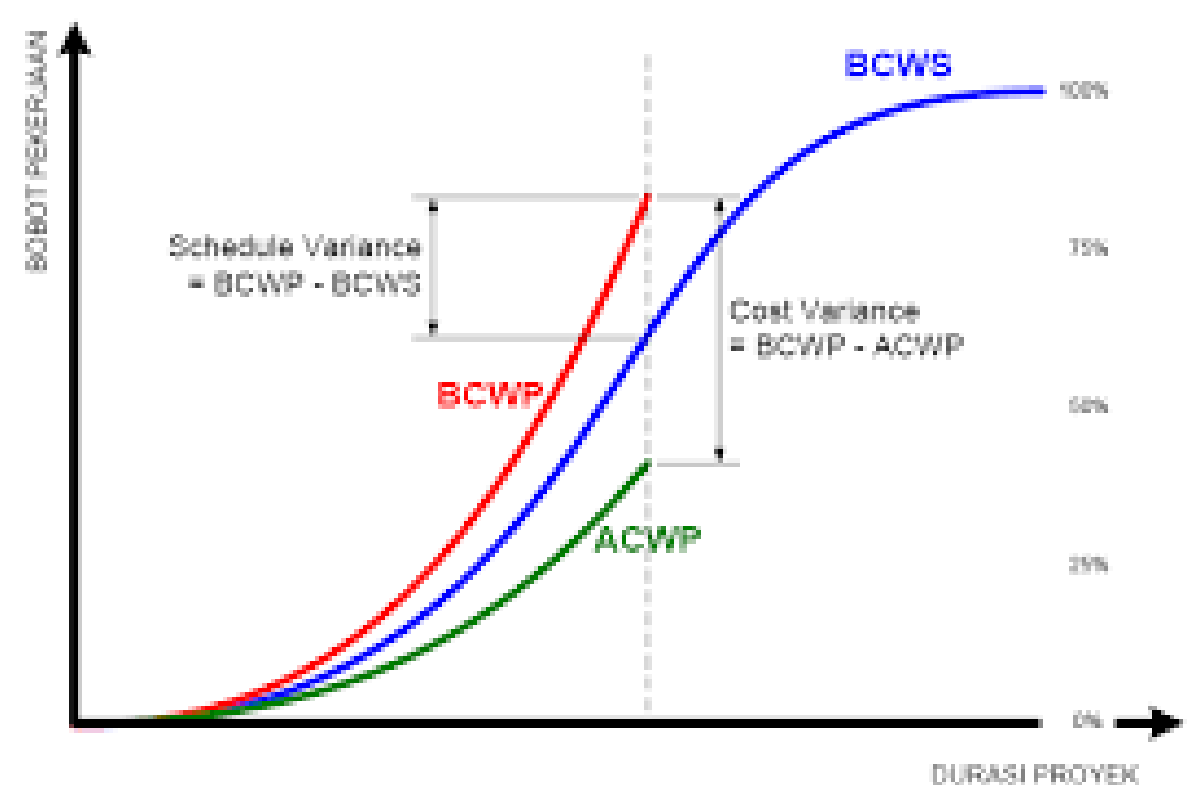

Sumber: Iman Soeharto (1995)

Gambar 1. Hubungan antara BCWP,BCWS, dan ACWP

Indikator-indikator yang digunakan yaitu :

Biaya Aktual atau ACWP (Actual Cost of Work Performed)

Menurut Iman Soeharto ACWP (Actual Cost of Work Performed) adalah jumlah biaya aktual pekerjaan yang telah dilaksanakan pada kurun waktu pelaporan tertentu.

\section{Jadwal anggaran atau BCWS (Budgeted Cost of Work Schedule)}

Menurut Iman Soeharto BCWS (Budgeted Cost of Work Schedule) menunjukkan anggaran untuk suatu paket pekerjaan yang disusun dan dikaitkan dengan jadwal pelaksanaan.

\section{Nilai hasil atau BCWP (Budgeted Cost of Work Performed)}

Menurut Iman Soeharto BCWP (Budgeted Cost of Work Performed) adalah nilai pekerjaan yang telah selesai terhadap anggaran yang disediakan untuk melaksanaan pekerjaan tersebut. Bila angka ACWP dibandingkan dengan BCWP, akan terlihat perbandingan biaya yang telah dikeluarkan untuk pekerjaan yang telah terlaksana terhadap biaya yang seharusnya dikeluarkan untuk maksud tertentu.

\section{Faktor-Faktor Indikator Kemajuan dan Kinerja Proyek}

Adapun indikator-indikator kemajuan dan kinerja proyek yaitu :

1. Varians Biaya atau CV (Cost Variance) digunakan untuk menghitung perbedaan antara nilai yang diperoleh setelah menyelesaikan bagian pekerjaan dengan biaya aktual yang pekerjaan yang diselesaikan lebih rendah dibandingkan dengan biaya yang sudah dikeluarkan. Menurut Iman Soeharto (2001), rumus Cost Variance adalah :

$\mathrm{CV}=\mathrm{BCWP}-\mathrm{ACWP}$ 2

2. Varians jadwal atau SV (Schedule Variance) digunakan untuk menghitung penyimpangan antara BCWS dengan BCWP. Menurut Iman Soeharto (2001), rumus Schedule Variance adalah : 
Siti Umi Azizah et al, Analisa Nilai Hasil Terhadap Waktu pada Proyek Pembangunan Gedung Laboratorium FKIP Tahap IV (Lanjutan) Universitas Jambi

Tabel 1. Analisis varians terpadu

\begin{tabular}{|c|c|c|}
\hline Varians Jadwal SV & Varians Biaya CV & Keterangan \\
\hline Positif & Positif & $\begin{array}{l}\text { Pekerjaan terlaksana lebih cepat dari pada jadwal dengan biaya lebih } \\
\text { kecil dari pada anggaran. }\end{array}$ \\
\hline Nol & Positif & $\begin{array}{l}\text { Pekerjaan terlaksana tepat sesuai jadwal dengan biaya lebih rendah } \\
\text { dari pada anggaran. }\end{array}$ \\
\hline Positif & Nol & $\begin{array}{l}\text { Pekerjaan terlaksana sesuai anggaran dan selesai lebih cepat dari pada } \\
\text { jadwal. }\end{array}$ \\
\hline Nol & Nol & Pekerjaan terlaksana sesuai jadwal dan anggaran. \\
\hline Negatif & Negatif & $\begin{array}{l}\text { Pekerjaan selesai terlambat dan menelan biaya lebih tinggi dari pada } \\
\text { anggaran. }\end{array}$ \\
\hline Nol & Negatif & $\begin{array}{l}\text { Pekerjaan terlaksana sesuai jadwal dengan menelan biaya diatas } \\
\text { anggaran. }\end{array}$ \\
\hline Negatif & & Pekerjaan selesai terlambat dan menelan biaya sesuai anggaran. \\
\hline Positif & Negatif & $\begin{array}{l}\text { Pekerjaan selesai lebih cepat dari pada rencana dengan menelan biaya } \\
\text { diatas anggaran. }\end{array}$ \\
\hline
\end{tabular}

Sumber : Imam Suharto(2001)

\section{Indeks Produktivitas dan Kinerja}

1. Indeks Kinerja Biaya atau CPI (Cost Performance Index) yaitu faktor efisiensi biaya yang telah dikeluarkan dapat diperlihatkan dengan membandingkan nilai pekerjaan yang secara fisik telah diselesaikan (BCWP) dengan biaya yang telah dikeluarkan dalam periode yang sama (ACWP). Menurut Iman Soeharto (2001), rumus Cost Performance Index adalah:

$\mathbf{C P I}=\frac{\text { BCWP }}{\text { ACWP }}$

2. Indeks Kinerja Jadwal atau SPI (Schedule Performance Index) yaitu faktor efisiensi kinerja dalam menyelesaikan pekerjaan dapat diperlihatkan oleh perbandingan antara nilai pekerjaan yang secara fisik telah diselesaikan (BCWP) dengan rencana pengeluaran biaya yang dikeluarkan berdasarkan rencana pekerjaan (BCWS). Menurut Iman Soeharto (2001), rumus SchedulePerformance Index adalah :

SPI $=\frac{\text { BCWP }}{\text { BCWS }}$

\section{Critical Ratio (CR)}

Critical Ratio (CR) merupakan sebuah angka indeks yang dihitung dengan membagi waktu yang tersisa hingga batas waktu pekerjaan dengan pekerjaan tersisa. Untuk mencari critical ratio dapat menggunakan rumus sebagai berikut:

\section{Proyeksi Biaya dan Jadwal Akhir Proyek}

Menurut Iman Soeharto (2001), berikut rumus proyeksi biaya dan jadwal akhir proyek adalah:

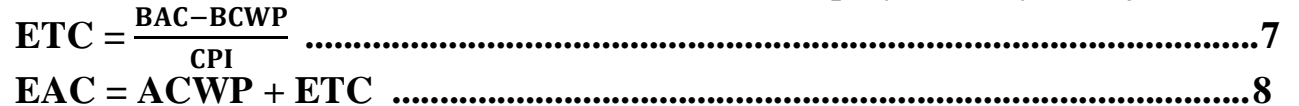
8

Prakiraan waktu penyelesaian seluruh pekerjaan :

ETS $=\frac{\text { Sisa Waktu }}{\text { SPI }}$

EAS $=$ Waktu Selesai + ETS

Keterangan :

EAC $($ Estimate At Completion $)=$ Prakiraan total biaya proyek

ETC (Estimate Temporary Cost $)=$ Prakiraan biaya untuk pekerjaan tersisa

BAC $($ Budgeted At Completion $)=$ Anggaran biaya proyek keseluruhan

ETS (Estimate Temporary Schedule) = Prakiraan waktu untuk pekerjaan yang tersisa

EAS $($ Estimate At Schedule $)=$ Prakiraan total waktu proyek

\section{METODE}

Jenis Data

1. Data Primer

2. Data Sekunder 
Siti Umi Azizah et al, Analisa Nilai Hasil Terhadap Waktu pada Proyek Pembangunan Gedung Laboratorium FKIP Tahap IV (Lanjutan) Universitas Jambi

\section{Pengumpulan Data}

1. Rencana Anggaran Biaya (RAB)

2. Time schedule

3. Laporan mingguan proyek

4. Laporan harian

\section{Metode Pengumpulan Data}

1. Metode Wawancara

2. Metode Observasi

3. Metode Pustaka

\section{Tempat Penelitian}

Nama Pekerjaan: Pembangunan Gedung Laboratorium FKIP Tahap IV (Lanjutan) Universitas Jambi

Lokasi Pekerjaan: Jl. Lintas Jambi - Muara Bulian Km 15, Mendalo Darat, Jambi Luar Kota, Kabupaten Muaro Jambi.

\section{Diagram Alir Penelitian}

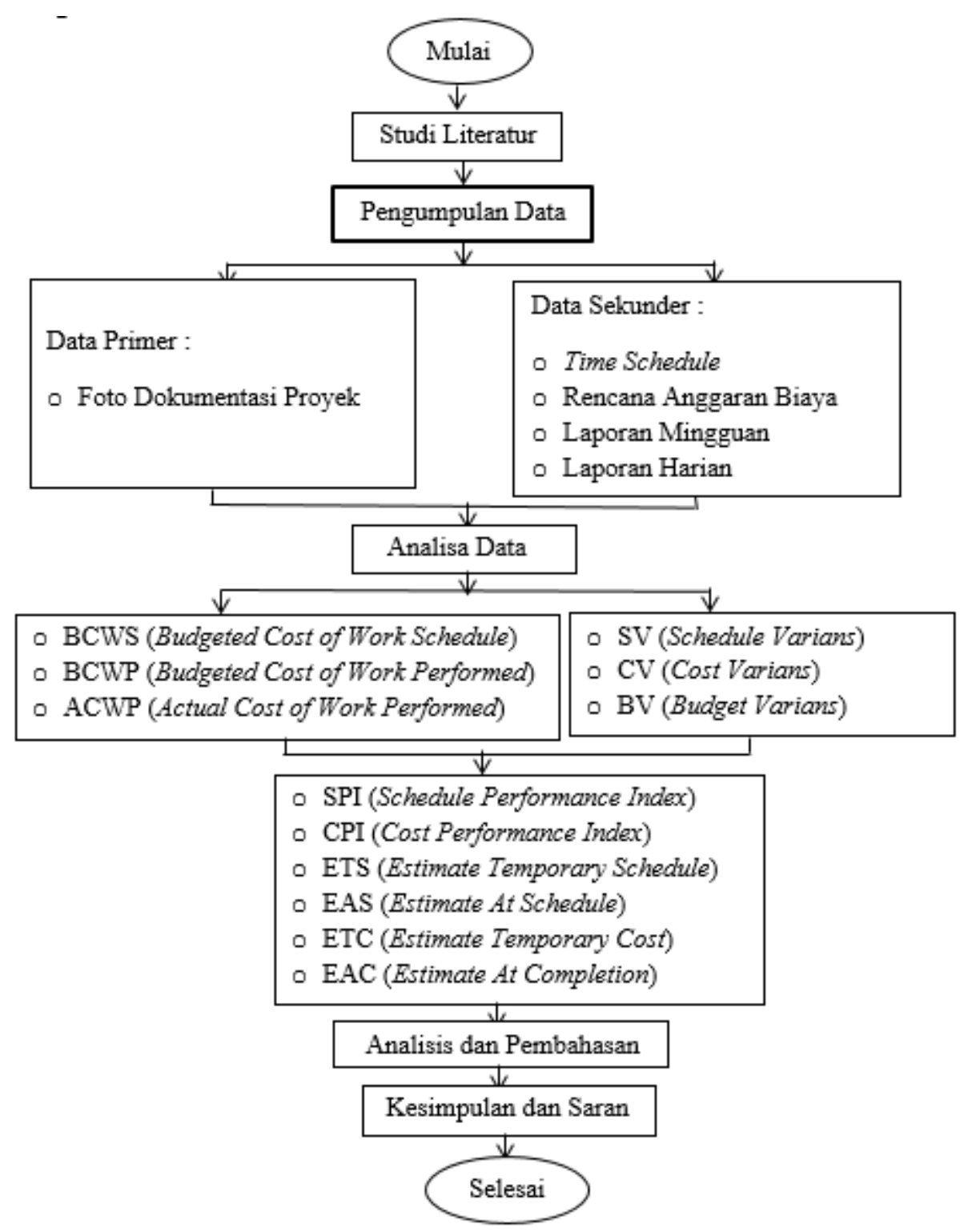

Sumber : Data olahan (2019)

Gambar 2. Diagram Alir Penelitian 


\section{HASIL DAN PEMBAHASAN}

\section{Analisis Budget Cost Of Work Schedule (BCWS)}

Analisa jumlah anggaran biaya yang dialokasikan berdasarkan rencana kerja yang telah disusun terhadap waktu (BCWS), Anggaran yang dimiliki oleh proyek sesuai dengan kegiatan yang dihitung berdasarkan persentase terhadap biaya total sesuai dengan yang telah dijelaskan yaitu selama 24 minggu. Berikut adalah contoh perhitungan BCWS pada minggu ke 1:

Perhitungan BCWS pada minggu ke 1 bulan Juni 2019

$\%$ Bobot rencana minggu ke 1 Juni $2019=0,19$

Nilai kontrak proyek atau anggaran $=$ Rp. 17.384.700.000,00

$\mathrm{BCWS}=(\%$ penyelesaian $) \times($ anggaran $)$

$=0,19 \% \times$ Rp. $17.384 .700 .000,00$

$=$ Rp. 33.030.930,00

\section{Analisis Budgeted Cost of Work Performed (BCWP)}

Berdasarkan data dari laporan mingguan proyek dapat diperoleh nilai BCWP perminggunya. Berikut adalah contoh perhitungan BCWP pada minggu ke 1:

Perhitungan BCWP pada minggu ke 1 bulan Juni 2019

$\%$ Bobot rencana minggu ke 1 bulan Juni $2019=0,00$

Nilai kontrak proyek atau anggaran $=$ Rp. 17.384.700.000,00

$\mathrm{BCWP}=(\%$ penyelesaian $) \times($ anggaran $)$

$=0,00 \% \times$ Rp. $17.384 .700 .000,00$

$=$ Rp. 0

\section{Analisis Actual Cost of Work Performed (ACWP)}

Menurut (George J. Ritz, 1994) biaya langsung proyek 85\% dari total biaya konstruksi dan biaya tak langsung proyek $15 \%$ dari total biaya konstruksi. Berikut adalah rumus total biaya konstruksi :

Total biaya konstruksi = Biaya langsung + Biaya tak langsung

0,85 total biaya konstruksi $=$ Biaya langsung

Total biaya konstruksi $=\frac{\text { Biaya langsung }}{0,85}$

Total biaya konstruksi $=\frac{12.602 .869 .300}{0,85}$

Total biaya konstruksi $=$ Rp. 14.826.905.060

Biaya tak langsung $\quad=0,15 \times$ Total biaya konstruksi

$=0,15 \times 14.826 .905 .060$

$=$ Rp. 2.224.035.759

Biaya tak langsung tiap minggu $=\frac{\text { Biaya tak langsung }}{\text { periode }}$

Biaya tak langsung tiap minggu $=\frac{2.224 .035 .759}{24 \text { minggu }}$

Biaya tak langsung tiap minggu $=$ Rp. 92.668.156

ACWP = Biaya langsung + Biaya tak langsung

$$
\begin{aligned}
& =\text { Rp. } 3 \cdot 079 \cdot 000,00+\text { Rp. } 92 \cdot 668 \cdot 156,00 \\
& =\text { Rp. } 95 \cdot 747 \cdot 156,00
\end{aligned}
$$

\section{Schedule Variance (SV)}

Schedule variance digunakan untuk menentukan apakah proyek yang sedang berjalan ini masih sesuai dengan jadwal rencana proyek atau tidak. Berikut adalah contoh perhitungan SV pada minggu ke 24 :

Perhitungan SV pada minggu ke 24 bulan November 2019

Nilai BCWP minggu ke 24 bulan November $2019=$ Rp. 13.768.682.400,00

Nilai BCWS minggu ke 24 bulan November $2019=$ Rp. 15.818.338.530,00

Varians Jadwal $(\mathrm{SV}) \quad=\mathrm{BCWP}-\mathrm{BCWS}$

$$
=\text { Rp. 13.768.682.400,00 - Rp. 15.818.338.530,00 }
$$

Rp. -2.049.656.130,00

Untuk mendapatkan nilai persen (\%) maka menggunakan rumus sebagai berikut : 


$$
\begin{aligned}
\text { Persen }(\%) & =\frac{\mathrm{SV}}{\mathrm{BCWP}} \times 100 \\
& =\frac{\mathrm{Rp} .-2.049 .656 .130,00}{\mathrm{Rp} .13 .768 .682 .400,00} \times 100 \\
& =-14,88 \%
\end{aligned}
$$

Dari hasil perhitungan SV maka diketahui dari awal pekerjaan hingga akhir pekerjaan hasilnya (-) atau di dapat dengan nilai penyimpangan terhadap waktu sebesar $-14,88 \%$. Hasil ini menunjukkan bahwa pelaksanaan pekerjaan terlambat dari jadwal rencana proyek.

\section{Cost Variance (CV)}

Cost Variance digunakan untuk menentukan apakah proyek yang sedang berjalan masih dalam batas anggaran atau melebihi anggaran rencana proyek. Berikut adalah contoh perhitungan CV pada minggu ke 24 :

Perhitungan CV pada minggu ke 24 bulan November 2019

Nilai BCWP minggu ke 24 bulan November $2019=$ Rp. 13.768.682.400,00

Nilai ACWP minggu ke 24 bulan November $2019=$ Rp. 14.665.397.100,00

Varians Biaya $(\mathrm{CV}) \quad=\mathrm{BCWP}-\mathrm{ACWP}$

$$
\begin{aligned}
& =\text { Rp. } 13.768 .682 .400,00-\text { Rp. } 14.665 .397 .100,00 \\
& =\text { Rp. }-896.714 .700,00
\end{aligned}
$$

Untuk mendapatkan nilai persen $(\%)$ maka menggunakan rumus sebagai berikut :

$$
\begin{aligned}
\text { Persen }(\%) & =\frac{\mathrm{CV}}{\mathrm{BCWP}} \times 100 \\
& =\frac{\mathrm{Rp} .-896.714 .700,00}{\mathrm{Rp} .13 .768 .682 .400,00} \times 100 \\
& =-6,51 \%
\end{aligned}
$$

Dari hasil perhitungan CV dapat diketahui dari awal pekerjaan hingga akhir pekerjaan hasilnnya (-) atau di dapat dengan nilai penyimpangan terhadap biaya sebesar $-6,51 \%$. Hasil ini menunjukkan bahwa biaya lebih besar dari anggaran.

\section{Budget Variance (BV)}

Budget Variance digunakan untuk menentukan berapa persen (\%) penyimpangan pada proyek yang sedang berjalan tersebut. Berikut adalah contoh perhitungan BV pada minggu ke 24 :

Perhitungan BV pada minggu ke 24 bulan November 2019

Nilai BCWS minggu ke 24 bulan November $2019=$ Rp. 15.818.338.530,00

Nilai ACWP minggu ke 24 bulan November $2019=$ Rp. 14.665.397.100,00

Budget Varians (BV) = BCWS - ACWP

$$
\begin{aligned}
& =\text { Rp. 15.818.338.530,00-Rp. 14.665.397.100,00 } \\
& =\text { Rp. 1.152.941.430,00 }
\end{aligned}
$$

Untuk mendapatkan nilai persen (\%) maka menggunakan rumus sebagai berikut :

$$
\begin{aligned}
\text { Persen }(\%) & =\frac{\mathrm{BV}}{\mathrm{BCWS}} \times 100 \\
& =\frac{\mathrm{Rp} .1 .152 .941 .430,00}{\mathrm{Rp} .15 .818 .338 .530,00} \times 100 \\
& =7,28 \%
\end{aligned}
$$

Berdasarkan hasil perhitungan BV dapat diketahui bahwa dari awal pekerjaan sampai dengan minggu ke 24, penyimpangan anggaran sebesar 7,28\%. Hasil ini menunjukkan bahwa anggaran yang digunakan lebih besar dari pada anggaran yang telah direncanakan.

\section{Analisis Schedule Performance Index atau Indeks Kinerja Jadwal (SPI)}

Indeks kinerja digunakan untuk perkiraan penyelesaian pekerjaan dan berapa lama waktu yang dibutuhkan.

Berikut adalah contoh perhitungan SPI pada minggu ke 1:

Perhitungan SPI pada minggu ke 1 bulan Juni 2019

Nilai BCWP minggu ke 1 bulan Juni $2019=$ Rp. 0

Nilai BCWS minggu ke 1 bulan Juni $2019=$ = Rp. 33.030.930,00 
Indeks Kinerja Jadwal (SPI) $=\frac{\text { BCWP }}{\text { BCWS }}$

$$
\begin{aligned}
& =\frac{\text { Rp. } 0}{\text { Rp. 33.030.930,00 }} \\
& =\text { Rp. } 0
\end{aligned}
$$

Jadi, nilai SPI pada minggu ke 1 bulan Juni $2019=0$

Hasil ini menunjukkan bahwa nilai SPI $<1$, berdasarkan kriteria SPI ini berarti waktu pelaksanaan lebih lama atau lebih lambat dari jadwal yang telah direncanakan.

\section{Analisis Cost Performance Index atau Indeks Kinerja Biaya (CPI)}

Indeks kinerja biaya digunakan untuk mengetahui apakah biaya pengeluaran proyek tersebut sesuai dengan anggaran rencana atau tidak. Berikut adalah contoh perhitungan CPI pada minggu ke 1:

Perhitungan CPI pada minggu ke 1 bulan Juni 2019

Nilai BCWP minggu ke 1 bulan Juni $2019=$ = Rp. 0

Nilai ACWP minggu ke 1 bulan Juni $2019=$ = Rp. 95.747.156,00

Indeks Kinerja Biaya $(\mathrm{CPI}) \quad=\frac{\mathrm{BCWP}}{\mathrm{ACWP}}$

$$
\begin{aligned}
& =\frac{\text { Rp. } 0}{\text { Rp. } 95 \cdot 747 \cdot 156,00} \\
& =\text { Rp. } 0
\end{aligned}
$$

Jadi, nilai CPI pada minggu ke 1 bulan Juni $2019=0$

Hasil ini menunjukkan bahwa nilai CPI < 1, berdasarkan kriteria CPI ini berarti kinerja pengeluaran lebih besar dari pada anggaran yang direncanakan.

\section{Estimate Temporary Schedule atau Prakiraan Waktu (ETS)}

Estimate Temporary Schedule (ETS) digunakan untuk mengetahui prakiraan waktu pekerjaan suatu proyek yang sedang berjalan. Berikut adalah contoh perhitungan ETS pada minggu ke 24:

Perhitungan ETS pada minggu ke 24 bulan November 2019

$\begin{array}{ll}\text { Nilai SPI } & =0,87 \\ \text { Total waktu } & =26 \mathrm{minggu} \\ \text { Waktu yang telah dilalui } & =24 \text { minggu }\end{array}$

Sisa waktu pelaksanaan $=26-24=2$ minggu

Jadi, ETS $=\frac{\text { Sisa waktu }}{\text { SPI }}$

$$
\begin{aligned}
& =\frac{2}{0,87} \\
& =2,29 \text { minggu }
\end{aligned}
$$

\section{Estimate At Schedule (EAS)}

Estimate At Schedule digunakan untuk mengetahui prakiraan waktu penyelesaian proyek. $\Delta \mathrm{S}$ digunakan untuk mengetahui prakiraan total waktu penyelesaian proyek. Berikut adalah contoh perhitungan EAS dan $\Delta \mathrm{S}$ pada minggu ke 24:

Perhitungan EAS dan $\Delta$ S pada minggu ke 24 bulan November 2019

Waktu yang telah di lalui $\quad=24$ minggu

Nilai ETS minggu ke 24=2,29

Jadi, EAS = Waktu yang telah dilalui + ETS

$$
\begin{aligned}
& =24+2,29 \\
& =26,29 \text { minggu }
\end{aligned}
$$

Total waktu

$=26$ minggu

Nilai EAS minggu ke 24

$$
=26 \text { minggu }
$$

Jadi, $\Delta \mathrm{S}=$ EAS - Total waktu

$$
\begin{aligned}
& =26,29-26 \\
& =0,29
\end{aligned}
$$


Siti Umi Azizah et al, Analisa Nilai Hasil Terhadap Waktu pada Proyek Pembangunan Gedung Laboratorium FKIP Tahap IV (Lanjutan) Universitas Jambi

\section{Estimate Temporary Cost (ETC)}

Estimate Temporary Cost digunakan untuk mengetahui prakiraan biaya untuk pekerjaan tersisa suatu proyek.

Berikut adalah contoh perhitungan ETC pada minggu ke 24:

Perhitungan ETC pada minggu ke 24 bulan November 2019

Total anggaran proyek $(\mathrm{BAC}) \quad=17.384 .700 .000,00$

Nilai BCWP minggu ke $24=13.768 .682 .400,00$

Nilai CPI minggu ke $24=0,94$

$\mathrm{ETC}=\frac{\mathrm{BAC}-\mathrm{BCWP}}{\mathrm{CPI}}$

$=\frac{17 \cdot 384 \cdot 700 \cdot 000,00-13 \cdot 768 \cdot 682 \cdot 400,00}{0,94}$

$=$ Rp. 3.846.827.234,00

\section{Estimate At Completion (EAC)}

Estimate At Completion (EAC) dapat dihitung dengan menggunakan beberapa asumsi, yaitu:

1. Estimate At Completion (EAC) dengan menganggap kinerja biaya pada masa yang akan datang sama dengan kinerja sebelumnya.

Berikut perhitungan EAC pada minggu ke 24 bulan November 2019 adalah :

Nilai ACWP minggu ke $24=14.665 .397 .100,00$

Nilai ETC minggu ke $24 \quad=3.846 .827 .234,00$

$\mathrm{EAC}=\mathrm{ACWP}+\mathrm{ETC}$

$=14.665 .397 .100,00+3.846 .827 .234,00$

$=$ Rp. 18.512.224.334,00

Dengan, sisa anggaran $=\mathrm{BAC}-\mathrm{EAC}$

$$
\begin{aligned}
& =\text { Rp. 17.384.700.000,00 - Rp. 18.512.224.334,00 } \\
& =\text { Rp. }-1.127 .524 .334,00
\end{aligned}
$$

2. Estimate At Completion (EAC) dengan menganggap kinerja biaya pada masa yang akan datang dipengaruhi oleh kinerja penjadwalan sebelumnya.

$$
\begin{aligned}
\text { EAC } & =\frac{\text { ACWP }+ \text { BAC }- \text { BCWP }}{\text { CPI } \times \text { SPI }} \\
& =\frac{\text { Rp.14.665.397.100,00+Rp.17.384.700.000,00 }- \text { Rp. } 13.768 .682 .400,00}{0,94 \times 0,87} \\
& =\text { Rp. } 9.125 .513 .370,00
\end{aligned}
$$

Maka, sisa anggaran $=\mathrm{BAC}-\mathrm{EAC}$

$$
\begin{aligned}
& =\text { Rp. } 17.384 .700 .000,00-\text { Rp. } 9.125 .513 .370,00 \\
& =\text { Rp. } 8.259 .186 .630,00
\end{aligned}
$$

3. Estimate At Completion (EAC) dengan menganggap kinerja biaya pada masa yang akan datang dipengaruhi oleh indeks kinerja waktu dan indeks kinerja biaya

$$
\begin{aligned}
& \mathrm{EAC}= \frac{\mathrm{ACWP}+\mathrm{BAC}-\mathrm{BCWP}}{0,18 C \mathrm{CI}+0,2 \mathrm{SPI}} \\
&=\frac{\text { Rp.14.665.397.100,00+Rp.17.384.700.000,00-Rp. } 13.768 .682 .400,00}{(0,18 \times 0,94)+(0,2 \times 0,87)} \\
&=\text { Rp. } 53.768 .866 .765,00 \\
& \begin{aligned}
\text { Maka, sisa anggaran }= & \text { BAC }- \text { EAC } \\
& =\text { Rp. } 17.384 .700 .000,00-\text { Rp. } 53.768 .866 .765,00 \\
& =\text { Rp. }-36.384 .166 .765,00
\end{aligned}
\end{aligned}
$$

\section{Critical ratio $(\mathbf{C R})$}

Critical ratio (CR) digunakan untuk mengetahui pekerjaan pada proyek yang sedang berjalan tersebut sesuai atau tidak dengan jadwal rencana. Berikut adalah perhitungan rasio kritis pada minggu ke 24 bulan November 2019 :

Nilai SPI pada minggu ke $24=0,87$

Nilai CPI pada minggu ke $24=0,94$

Critical ratio $(\mathrm{CR}) \quad=\mathrm{SPI} \times \mathrm{CPI}$

$$
\begin{aligned}
& =0,87 \times 0,94 \\
& =0,82
\end{aligned}
$$

Keterangan : Dari hasil perhitungan diatas maka diperoleh nilai CR yaitu 0,82. Hasil ini menunjukkan bahwa nilai CR $<1$, berdasarkan nilai-nilai CR ini berarti pekerjaan tersebut terlambat dari jadwal dan pekerjaan tersebut membutuhkan perhatian khusus. 


\section{SIMPULAN}

Berdasarkan hasil penelitian yang telah dilakukan, maka dapat diambil kesimpulan yaitu :

1. Pada minggu ke 26 sesuai dengan kesimpulan bahwa pelaksanaan pekerjaan terlambat dari jadwal rencana proyek dan biaya lebih besar dari pada anggaran yang telah di rencanakan karena diminggu ke 24 untuk prakiraan biaya penyelesaian proyek sudah sebesar Rp. 18.512.224.334,00 dengan sisa anggaran sebesar Rp. -1.127.524.334,00 sedangkan total anggaran biaya proyek sebesar Rp. 17.384.700.000,00. Ini menunjukkan di minggu ke 24 sudah mengalami biaya yang lebih besar dari pada anggaran yang telah direncanakan.

2. Prakiraan waktu penyelesaian proyek sesuai dengan nilai kontrak adalah 26 minggu. Namun tidak sesuai dengan nilai kontrak yaitu 26,29 minggu.

\section{Saran}

Setelah penulis melakukan analisis data atau pengolahan data maka terdapat saran yaitu pengendalian jadwal dan biaya yaitu saling memiliki ketergantungan, maka dari itu untuk lebih efektif pengendalian jadwal dan biaya sebaiknya dilakukan secara harian agar dapat menghindari terjadinya penyimpangan jadwal dan biaya yang cukup besar yang bisa mengakibatkan pengendalian sulit dilakukan. Untuk itu agar senantiasa melakukan pengawasan terhadap biaya awal.

\section{DAFTAR PUSTAKA}

Arditi D. And Patel BK. 1989. Impact Analsysis Of Owner-Directed Acceleration. Journal of Construction Engineering and Management ASCE Vol 115, no. 1, pp.144-157

Austen, Neale. 1991. Manajemen Proyek Konstruksi. Jakarta: PT. Pustaka Binaman Pressindo

Ervianto, Wulfram I. 2002. Manajemen Proyek Konstruksi. Yogyakarta: Andi Offset

Husen Abrar. 2009. Manajemen Konstruksi Proyek Perencanaan, Penjadwalan, dan Pengendalian Proyek. Serpong: Andi

Soeharto Iman. 1995. Manajemen Proyek : Dari Konseptual Sampai Operasional. Jakarta: Erlangga

Soeharto Iman. 1997. Manajemen Proyek : Dari Konseptual Sampai Operasional. Jakarta: Erlangga

Soeharto Iman. 2001. Manajemen Proyek : Dari Konseptual Sampai Operasional Jilid II. Jakarta: Erlangga

Schwalbe, K. 2006. Introduction to Project Management. Minneapolis: Thomson Course Technology

Wibowo. 2002. Metode Analisis Waktu dan Biaya. Jakarta: Erlangga

Widiasanti Irika. 2011. Metode Nilai Hasil (Earned Value). Jakarta: Jurnal Ilmiah

Pabalik C. P. 2018. Analisis Nilai Hasil Terhadap Waktu Pada Proyek Konstruksi. Manado: Universitas Sam Ratulangi Manado.

Pamungkas Agung. 2013. Analisis Nilai Hasil Terhadap Waktu dan Biaya Pada Proyek Konstruksi. Surakarta: Universitas Sebelas Maret. 